Murgatroyd, L. B. (1976). The preparation of thin sections from glycol methacrylate embedded tissue using a standard rotary microtome. Medical Laboratory Sciences, $33,67-71$.

North, R. J. (1971). Methyl green-pyronin for staining autoradiographs of hydroxyethyl methacrylate-embedded lymphoid tissue. Stain Technology, 46, 59-62.

Ruddell, C. L. (1967a). Hydroxyethyl methacrylate combined with polyethylene glycol 400 and water; an embedding medium for routine 1-2 micron sectioning. Stain Technology, 42, 119-123.

Ruddell, C. L. (1967b). Embedding media for 1-2 micron sectioning. (2) Hydroxyethyl methacrylate combined with 2butoxyethanol. Stain Technology, 42, 253-255.

Ruddell, C. L. (1971). Embedding media for 1-2 micron sectioning. (3) Hydroxyethyl methacrylate-benzoyl peroxide activated with pyridine. Stain Technology, 46, 77-83.

Sims, B. (1974). A simple method of preparing 1-2 micron sections of larger tissue blocks using glycol methacrylate. Journal of Microscopy, 101, 223-227.

\section{Macrophage electrophoretic mobility test}

The report by Crozier et al. (1976) that the macrophage electrophoretic mobility test (MEM) is ineffective in the diagnosis of cancer is in full agreement with that of our group at Weston Park Hospital, Sheffield (Shelton et al., 1975). While the MEM test may be of value in the hands of highly specialist workers it is certainly of no present value outside such centres. It is interesting that a simple macrophage migration inhibition test to encephalitogenic factor gave similar results to the complex and capricious MEM test. It seems likely that further exploration and refinement of the simpler technique is a more hopeful approach to cancer diagnosis than the MEM test.

IAN CARR

Department of Pathology, University of Saskatchewan, University Hospital, Saskatoon, Saskatchewan, Canada $S 7 N$ OW8

\section{References}

Crozier, E. H., Hollinger, M. E., Woodend, B. E., and Robertson, J. H. (1976). An assessment of the macrophage electrophoretic mobility test (MEM) in cancer diagnosis. Journal of Clinical Pathology, 29, 608-609.

Shelton, J. B., Potter, C. W., and Carr, I. (1975). Cellular immunity to myelin basic protein in man and in animal model systems as measured by the macrophage migration inhibition test. British Journal of Cancer, 31, 528-534.

\section{Plasma paracetamol estimation}

Spooner et al. (1976) claim that the method of Routh et al. (1968), for the measurement of plasma paracetamol, is relatively insensitive and more susceptible to interference from other drugs than the method of Dordoni et al. (1973). Although we agree that the former procedure is less sensitive, we feel that this is not a practical problem in the investigation of suspected paracetamol overdose. In fact, the improved sensitivity which these authors obtain limits the linearity of the method to $1000 \mu \mathrm{mol} / \mathrm{l}$, necessitating some modification to the procedure in order to measure higher levels, which are often encountered in overdosage.

With regard to specificity, we have found no interference by phenobarbitone in the Routh procedure provided that the extraction is performed as originally described, that is, from ether into sodium bicarbonate solution before adjusting the pH. If this is omitted and the ether is shaken with sodium hydroxide solution instead, then barbiturate is extracted and does interfere.

Phenylbutazone is a problem in both procedures, and scanning of spectra is essential to minimise the risk of reporting false plasma paracetamol values (Wiener et al., 1976). Simply reading at one wavelength gives no indication of the presence of interfering compounds. Interference by phenylbutazone does not occur in the rapid colorimetric method described by Glynn and Kendal (1975), several modifications of which are now in use. In fact this method seems relatively free from the effects of other drugs with the exception of some sulphonamide preparations which could interfere at high concentration (Wiener, 1976).

K. WIENER and M. G. LONGLANDS Department of Clinical Biochemistry, The North Manchester General Hospital, Crumpsall, Manchester M8 6RB

\section{References}

Dordoni, B., Willson, R. A., Thompson, R. P. H., and Williams, R. (1973). Reduction of absorption of paracetamol by activated charcoal and cholestyramine: a possible therapeutic measure. British Medical Journal, 3, 86-87.
Glynn, J. P. and Kendal, S. E. (1975). עס Paracetamol measurement (Letter). Lancet, 1, 1147-1148.

Routh, J I., Shane, N. A., Arredondo, E. G., and Paul, W. D. (1968). Determination of $\mathrm{N}$-acetyl-p-aminophenol in plasma Clinical Chemistry, 14, 882-889.

Spooner, R. J., Reavey, P. C., and McIntosh, L. (1976). Rapid estimation of paracetamol $\frac{}{\sigma}$ in plasma (Letter). Journal of Clinical Pathology, 29, 663.

Wiener, K. (1976). Paracetamol estimation:ผ Comparison of a quick colorimetricmethod with a standard spectrophoto-metric method. Annals of Clinical Bio- $-\overrightarrow{ }$ chemistry, 13 (In press).

Wiener, K., Longlands, M. G., and Tan, B. H. A. (1976). Interference by oxyphen-O butazone in paracetamol estimation. $\omega$ Annals of Clinical Biochemistry, 13,. 452-453. 